\title{
ACKNOWLEDGEMENT TO REFEREES
}

(C) Springer International Publishing Switzerland 2016

Dear Reader,

As we approach the end of 2016, and publish our final issue of BioDrugs for the year, I wish to reflect on another successful year for the journal and for others in the Adis Premier journals portfolio, and to thank all who have contributed to BioDrugs over the past 12 months.

As of September 2016, BioDrugs' top 10 downloaded articles from SpringerLink this year were:

Fusion Proteins for Half-Life Extension of Biologics as a Strategy to Make Biobetters. Strohl, W.R. BioDrugs (2015) 29: 215. doi:10.1007/s40259-015-0133-6.

Physicochemical and Functional Comparability Between the Proposed Biosimilar Rituximab GP2013 and Originator Rituximab. Visser, J., Feuerstein, I., Stangler, T. et al. BioDrugs (2013) 27: 495. doi:10.1007/s40259-013-0036-3.

Pharmacovigilance Considerations for Biosimilars in the USA. Grampp, G. \& Felix, T. BioDrugs (2015) 29 : 309. doi:10.1007/s40259-015-0137-2.

Assessing the Immunogenicity of Biopharmaceuticals. Pineda, C., Castañeda Hernández, G., Jacobs, I.A. et al. BioDrugs (2016) 30: 195. doi:10.1007/s40259-016-0174-5.

Assessing Analytical Similarity of Proposed Amgen Biosimilar ABP 501 to Adalimumab. Liu, J., Eris, T., Li, C. et al. BioDrugs (2016) 30: 321. doi:10.1007/s40259-016-0184-3.

Demonstration of Functional Similarity of Proposed Biosimilar ABP 501 to Adalimumab. Velayudhan, J., Chen, Yf., Rohrbach, A. et al. BioDrugs (2016) 30: 339. doi:10.1007/s40259-016-0185-2.

Chimeric Antigen Receptor-Engineered T Cells for the Treatment of Metastatic Prostate Cancer. Hillerdal, V. \& Essand, M. BioDrugs (2015) 29: 75. doi:10.1007/s40259-015-0122-9.

Comparability of Biosimilar Filgrastim with Originator Filgrastim: Protein Characterization, Pharmacodynamics, and Pharmacokinetics. Sörgel, F., Schwebig, A., Holzmann, J. et al. BioDrugs (2015) 29: 123. doi:10.1007/s40259-015-0124-7

Controversies in Establishing Biosimilarity: Extrapolation of Indications and Global Labeling Practices. Ebbers, H.C. \& Chamberlain, P. BioDrugs (2016) 30: 1. doi:10.1007/s40259-015-0154-1.

RNA Interference Technologies and Therapeutics. López-Fraga, M., Martínez, T. \& Jiménez, A. BioDrugs (2009) 23: 305. doi:10.2165/11318190-000000000-00000.

I offer my sincere thanks to all authors who have contributed articles to BioDrugs over the course of 2016. Their skill and dedication are critical to the continued publication of the journal. The quality of published articles is, similarly, testament to the significant efforts of the peer reviewers, whose commitment ensures that the journal's content is held to the highest possible standard. I would like to thank the following individuals who acted as reviewers for BioDrugs in the last 12 months:

Ivo Abraham, USA

Vincenzo Adamo, Italy
Yakup Aksoy, Turkey

Talha M. Al-Shawaf, UK 
Rieke Alten, Germany

Diego Alvarado, USA

Teruyo Arato, Japan

Brian A. Baldo, Australia

Ipsita Banerjee, USA

Herve Bard, France

Alain Beck, France

Daniel Bedinger, USA

David Bedwell, USA

Caroline L. Bellac, Switzerland

Shomron Ben-Horin, Israel

Charles L. Bennett, USA

Yevgeny Berdichevsky, USA

Matthew Bernett, USA

Irene Bezemer, The Netherlands

Maria Luisa Bianchi, Italy

François Bocquet, France

Balkiss Bouhaouala-Zahar, Tunisia

Matthieu Broussas, France

Kristina Buder, Germany

Santos Castaneda, Spain

Gilberto Castañeda Hernández, Mexico

Renato Caviglia, UK

Pierpaolo Ceci, Italy

Frederic Checler, France

Saima Chohan, USA

Christos Chouaï, France

Clay J. Cockerell, USA

Javier Diez-Domingo, Spain

Surjit B. Dixit, Canada

Alexander Dowell, UK

Eric Druyts, Canada

Natalie Duncan, USA

Orestis Efthimiou, Greece

Zeynep Eroglu, USA

Albert Farrugia, Australia

Mehdi Farshchian, Finland

Jin-Shan Feng, China

Edgardo Ferran, France

Willy A. Flegel, USA

Roy M. Fleischmann, USA

Giovanni Gabutti, Italy

James Galloway, UK

Pere Gascon, Spain

Krisztina Gecse, Hungary

Thijs J. Giezen, The Netherlands

Amanda Goh, Australia

Cheryl R. Greenberg, Canada

Matthew Gubens, USA

Luigi Gugliotta, Italy

Ersin Günay, Turkey

Gabriel Herrero-Beaumont, Spain

Paul Hofman, France
Christine Hofmann, Germany

Dörte Huscher, Germany

Giancarlo Icardi, Italy

Cristoforo Incorvaia, Italy

K. Jack Ishak, Canada

Joanna Jakubowicz-Gil, Poland

Xu-Rong Jiang, USA

Yangmee Kim, Republic of Korea

Jean Klastersky, Belgium

Joel M. Kremer, USA

Pekka Kurki, Finland

Zhenli Kwan, Malaysia

Pierre-Olivier Lang, Switzerland

Eun Bong Lee, Republic of Korea

Qiang Li, USA

Alexandra R. Lucas, USA

Margaret Ma, UK

Rajan Madhok, UK

Maria Elisa Mancuso, Italy

Grant McFadden, USA

Anders Mellemgaard, Denmark

Alberto Migliore, Italy

Mariya Moosajee, UK

Serge Muyldermans, Belgium

Ines Neundorf, Germany

Ina Oehme, Germany

Jaeryung Oh, Republic of Korea

Alexandra C. Pacurariu, The Netherlands

Won Park, Republic of Korea

Francesca Pasi, Italy

Sapna P. Patel, USA

Ian D. Pavord, UK

Adam Pluzanski, Poland

Lluís Puig, Spain

Mariusz J. Puszczewicz, Poland

Masmudur Rahman, USA

Anurag S. Rathore, India

Tadeusz Robak, Poland

Antonio Russo, Italy

Rajalingham Sakthiswary, Malaysia

Melody Sauerborn, Germany

Margit F. Serban, Romania

Alexander N. Shoushtari, USA

Hans-Christian Siebert, Germany

Charalampos Siristatidis, Greece

Mahmoud Soliman, South Africa

Kyriakos Souliotis, Greece

Jacqueline Stephens, USA

Michael W. Stewart, USA

Janakiraman Subramanian, USA

Beverly Teicher, USA

David Ternant, France

Erik Teugels, Belgium 
Mahdi Tondar, USA

Jean-Hugues Trouvin, France

Panagiotis Tsirigotis, Greece

Reaz Uddin, Pakistan

Leon A.G.J.M. van Aerts, The Netherlands

Eugene P. van Puijenbroek, The Netherlands

Robert J. Vassar, USA

Yowming Wang, USA
Limin Wang, USA

Kenneth White, UK

Matthias Wirth, Germany

Dae Hyun Yoo, Republic of Korea

Seo-Hyun Yoon, Republic of Korea

Gang Zhao, China

Weihua Zhou, USA

In addition, I would like to thank the members of the journal's Honorary Editorial Board, who have acted as peer reviewers and authors, and have provided guidance on journal content, policy and processes:

L. Bergmann, Klinikum der Johann Wolfgang GoetheUniversitat, Frankfurt, Germany

E. De Clercq, Rega Instituut, Leuven, Belgium

G. D. Demetri, Dana Farber Cancer Institute, Boston, MA, USA

T. R. Flotte, University of Massachusetts Medical School, Worcester, MA, USA

P. Fournier, German Cancer Research Center, Heidelberg, Germany

T. M. Ganey, Atlanta Medical Center, Atlanta, GA, USA

A. Ganser, Hannover Medical School, Hannover, Germany

H.-P. Gerber, Pfizer, New York, NY, USA

B. Groner, Georg-Speyer-Haus, Institute for Biomedical Research, Frankfurt, Germany

F. Guilhot, Université de Poitiers, Poitiers, France

W. H. Hildebrand, University of Oklahoma, Oklahoma City, OK, USA

B. D. Kahan, University of Texas, Houston, TX, USA

A. Kamb, Amgen Inc., South San Franscisco, CA, USA

S. L. Lightman, Moorfields Eye Hospital, London, UK
P. Moingeon, Stallergenes, Paris, France

D. Müller, Universitat Stuttgart, Stuttgart, Germany

J. L. Murray, University of Texas MD Anderson Cancer Center, Houston, TX, USA

C. Picado, Hospital Clinic de Barcelona, Barcelona, Spain

T. Schirrmann, YUMAB GmbH, Braunschweig, Germany

$P$. Spence, GlobalAcorn Ltd., London, England

C. A. Stein, City of Hope Medical Center, Duarte, CA, USA

R. C. Stevens, University of Southern California, Los Angeles, CA, USA

W. R. Strohl, BiStro Biotech Consulting, Bridgewater, NJ, USA

B. A. Sullenger, Duke University Medical Center, Durham, NC, USA

J. Terrett, CtyomX Therapeutics, Inc., CA, USA

P. Trzonkowski, Medical University of Gdansk, Gdansk, Poland

J. W. Van der Meer, University Medical Center St. Radboud, Nijmegen, The Netherlands

To Adis journal portfolio news, mid-2016 saw the release of the ISI Journal Citation Reports and the latest journal impact factors. The impact factor for BioDrugs remained relatively stable at 2.867 . The majority of our other journals saw a rise in impact factor against the previous year. Most notably, five of our journals saw an increase of over $10 \%$ in impact factor-The Patient (17.08\%), Clinical Drug Investigation (15.99\%), the American Journal of Clinical Dermatology (13.17\%), Drug Safety (13.5\%), and Drugs (12.43\%).

Another important milestone was reached for our recently launched open access journals, Drug Safety-Case Reports and Drugs-Real World Outcomes. Content from these journals is now available on PubMed Central.

The Adis journals portfolio will expand in 2017, with the launch of PharmacoEconomics-Open. This new journal will be fully open access and will focus on the publication of applied research on the economic implications and health outcomes associated with drugs, devices and other healthcare interventions. It joins our other well respected health outcomes publications, PharmacoEconomics, Applied Health Economics and Health Policy, and The Patient: PatientCentered Outcomes Research.

I hope that you have found the articles published throughout 2016 to be both interesting and informative. I have appreciated the high quality of content contributed to the journal this year and I look forward to keeping you up to date with topical issues in the clinical biotechnology field in 2017.

With best wishes from Kathy Fraser, Editor. 